\title{
Characteristics of iron oxide rust prepared by peracetic acid and its removal of heavy metals in water
}

\author{
Sunyu Jung ${ }^{1, *}$ and Soon-Ho Park ${ }^{2}$ \\ ${ }^{1}$ Korean Minjok Leadership Academy, Gangwon-do 25268, Korea \\ ${ }^{2}$ Glory\&Tech Co., Seoul 04048, Korea
}

\begin{abstract}
Fe}_{2} \mathrm{O}_{3}$ is an especially promising material for water purification as it shows high heavy metal adsorption capacity. However, the high cost of commercial $\mathrm{Fe}_{2} \mathrm{O}_{3}$ makes it difficult to be widely used in developing countries. Herein, we probe the heavy metal removal performance of iron oxide rust. Rust was grown on iron nails in a controlled manner using peracetic acid $\left(\mathrm{CH}_{3} \mathrm{CO}_{3} \mathrm{H}\right)$, a safe and environmentfriendly oxidizer. Arsenic was selected as an example of a heavy metal contaminant in this study. XRD and EDS analysis revealed that the iron oxide prepared with peracetic acid was nearly amorphous $\mathrm{Fe}_{2} \mathrm{O}_{3}$. Amorphous iron oxide is reported to show higher reactivity than crystalline iron oxide. The BET specific surface area of prepared $\mathrm{Fe}_{2} \mathrm{O}_{3}$ is $71 \mathrm{~m}^{2} / \mathrm{g}$, which is larger than that of commercial $\mathrm{Fe}_{2} \mathrm{O}_{3}$, and the average pore diameter is $73 \AA$. Oxidized nails are highly effective for removing heavy metals: about $90 \%$ of $1 \mathrm{ppm}$ arsenic in water was removed at the residence time of 20 minutes, and the removal rate of $90 \%$ is maintained after 10 back-to-back arsenic removal experiments at the same residence time. Iron oxide prepared in this study can remove, per $1 \mathrm{~cm}^{2}$, up to $0.114 \mathrm{mg}$ of arsenic.
\end{abstract}

\section{Introduction}

Groundwater contamination by heavy metals such as $\mathrm{Cd}$, $\mathrm{As}$, and $\mathrm{Cr}$ is one of the biggest public health concerns in developing countries, e.g. Laos, Bangladesh, Cambodia, and Vietnam. Although a myriad array of materials has been studied for heavy metal removal, metal oxides such as $\mathrm{Fe}_{2} \mathrm{O}_{3}$ are especially promising as they show high heavy metal adsorption capacity [1]. However, the high cost of $\mathrm{Fe}_{2} \mathrm{O}_{3}$ makes it difficult to be widely used in developing countries. Therefore, there is a currently a growing demand for appropriate technology for heavy metal removal.

Herein, we probe the heavy metal removal performance of iron oxide rust formed on the surface of Nails. Rust was grown on iron nails in a controlled manner using Peracetic acid $\left(\mathrm{CH}_{3} \mathrm{CO}_{3} \mathrm{H}\right)$, a safe and environment-friendly oxidizer [2]. Arsenic was selected as an example contaminant in this study as it is typically present in the water of South Asian countries.

Specific research objectives are determined the optimal condition for iron nail oxidation, characterize the iron oxide formed on the nail surface, and evaluate the heavy metal removal capacity of oxidized nails in water samples.

\section{Materials \& Methods}

\subsection{Procedure for the Oxidation of Nails}

Commercial iron nails were oxidized using peracetic acid, $\mathrm{CH}_{3} \mathrm{CO}_{3} \mathrm{H}$. Peracetic acid is an environment-friendly oxidizer because it decomposes to acetic acid and hydrogen peroxide, both of which are biodegradable. Iron nails were 1 inch long and was about $0.57 \mathrm{~g}$ per nail. The geometric surface area of a nail was about $1.7 \mathrm{~cm}^{2}$.

The surface oxide layer of the nail was removed using a sandpaper, and the nail was rinsed with deionized water. Cleaned nails were oxidized by submerging them in an aqueous solution with $10 \mathrm{wt} \%$ peracetic acid and $\mathrm{NaCl}$, which was added to improve conductivity. In order to compare different oxidation methods, nails were also oxidized with nitric acid. After oxidizing nails for a desired amount of time, nails were taken out of oxidizing solutions and rinsed with copious amounts of deionized water to stop to oxidation process, after which they were dried in air.

\subsection{Characterization of rust on oxidized nails}

The surface structure of oxidized iron nails was studied was studied with an optical microscope and SEM (JEOL $7610 \mathrm{~F}$ ). EDS was used to analyse the change in atomic ratios before and after the oxidation reaction. Moreover, XRD (Panalytical Xpert) and BET (Micromeritics 2010) were used to study the crystallinity of the rust, and the specific surface area and pore diameter, respectively.

\subsection{Arsenic removal using rust on oxidized nails}

\footnotetext{
* Corresponding author: sunyuj@naver.com
} 
Aqueous arsenic solution was prepared by dissolving sodium arsenate $\left(\mathrm{Na}_{2} \mathrm{HAsO}_{4} \cdot 7 \mathrm{H}_{2} \mathrm{O}\right.$, Sigma-Aldrich) at 1 ppm, which is 100 times the standard for drinking water.

A device for heavy metal removal was constructed using a glass column with an internal diameter of $34 \mathrm{~mm}$ and a length of $400 \mathrm{~mm}$ packed with oxidized nails. Arsenic solution was flown through the column and arsenic removal rate was measured as a function of residence time. The concentration of arsenic in the solution was measured using ICP (Leeman Labs).

We also wanted to evaluate the long-term performance of the heavy metal removal device. We measured the arsenic removal rate after 10 repeated experiments at a constant residence time. To quantify the maximum arsenic adsorption per surface area of iron oxide, oxidized nails were submerged in a $10 \mathrm{ppm}$ arsenic solution and arsenic removal rate was measure after 12 hours.

\section{Results}

\subsection{Change in surface structure as a function of oxidation time}

The iron oxide layer at various oxidation times was observed using an optical microscope (Fig. 1). After 30 minutes of oxidation, islands of iron oxide have been formed, but after 1 hour, most of the iron surface was covered with the oxide layer but it was not uniform. After 2 hours the oxide layer has completely covered the surface and no further oxidation was observed. After 8 hours some of the oxide layer began to peel off, and after 24 hours it was severely damaged. Together, this suggests that 2 hours is the optimum duration of oxidation reaction.

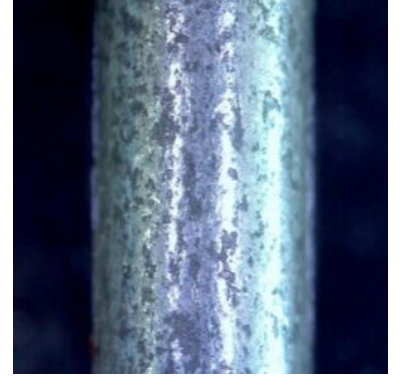

before oxidation

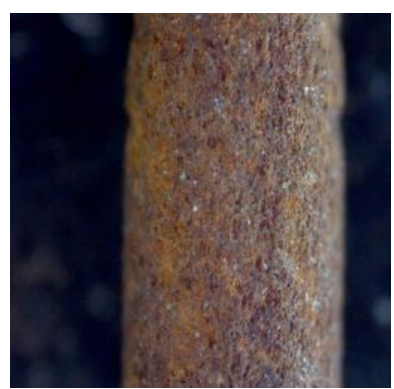

after 1 hour

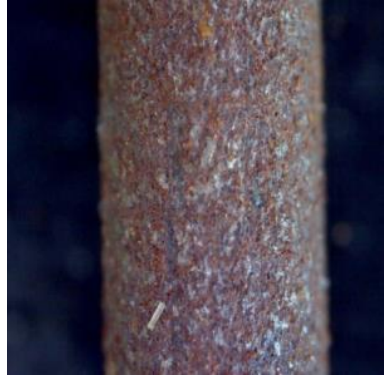

after 30 minutes

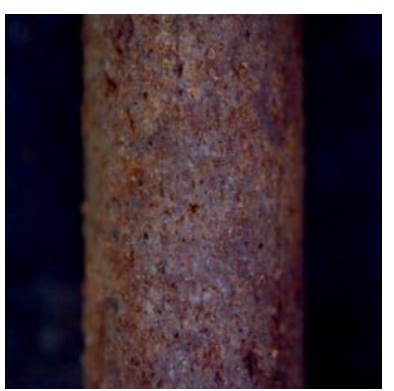

after 2 hours

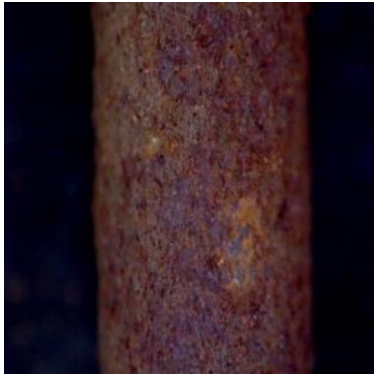

after 8 hours

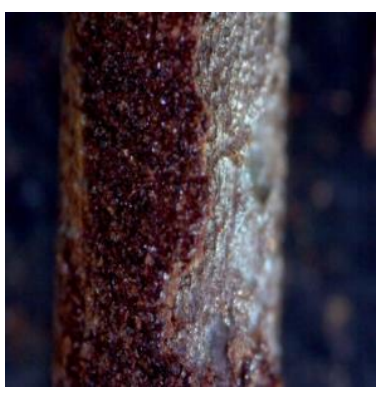

after 24 hours
Fig. 1. Optical microscope images of nail surfaces at various oxidation times.

\subsection{SEM analysis}

SEM images of iron nails oxidized with peracetic acid for 2 hours were taken. As shown in Fig. 2, the oxide layer is uniformly form on the surface in the 100x image, and oxide crystals and pores of various sizes are observed in the $2000 x$ image.

\subsection{EDS analysis}

EDS analysis results of nails before and after oxidation, as well as after arsenic adsorption are shown in Fig. 3. Before oxidation with peracetic acid (Fig. 3a), the iron nail surface contains about $11 \%$ oxidation due to oxidation in air. Carbon was detected, presumably due to coating material on iron nails designed to prevent corrosion. Figs. $3 \mathrm{~b}$ and $3 \mathrm{c}$ were taken after oxidation to form iron oxide; the atomic ratio of $\mathrm{O}$ increased. For both sets of data, the $\mathrm{Fe}: \mathrm{O}$ ratio is $1: 1.47$ on average, suggesting that the identity of the iron oxide formed is $\mathrm{Fe} 2 \mathrm{O} 3$ ( $\mathrm{Fe}: \mathrm{O}=1: 1.5)$. $\mathrm{Cl}$ detected in Fig. $3 \mathrm{~b}$ is from added $\mathrm{NaCl}$ in the oxidation solution, and arsenic can be detected in Fig. 3c due to adsorbed arsenic on iron oxide after arsenic removal experiment.

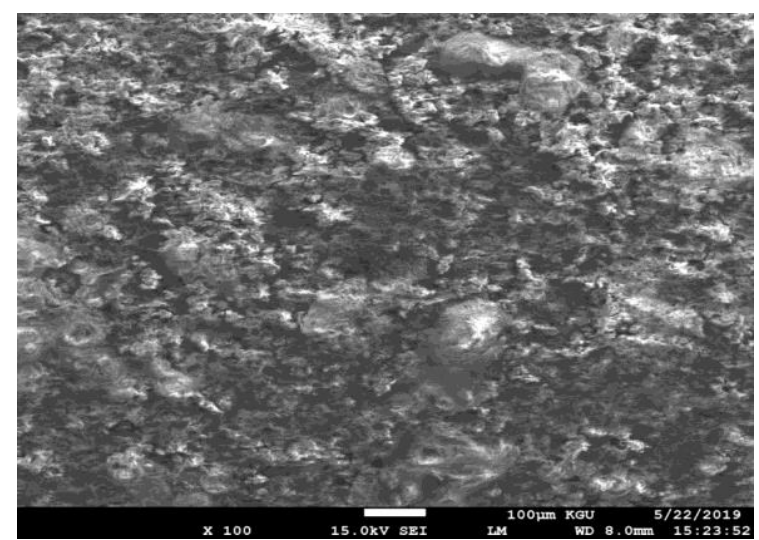

(a) $\times 100$ 


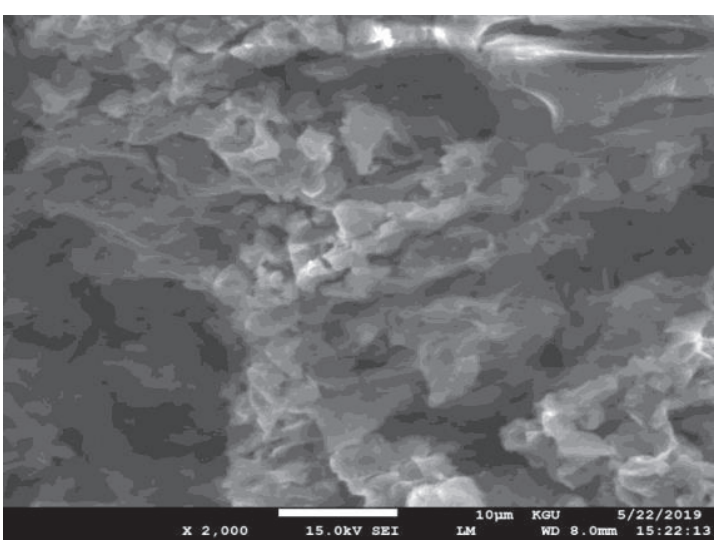

(b) $\mathrm{x} 2000$

Fig. 2. SEM images of iron oxide on oxidized nail surface. (above x 100, below x 2000)

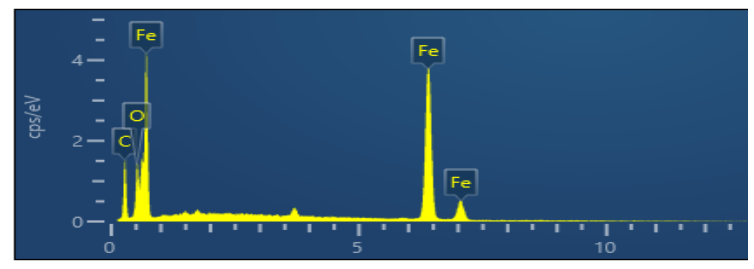

\begin{tabular}{|c|c|c|}
\hline Element & Weight \% & Atomic \% \\
\hline $\mathrm{C}$ & 17.94 & 46.38 \\
\hline $\mathrm{O}$ & 5.79 & 11.23 \\
\hline $\mathrm{Fe}$ & 76.27 & 42.40 \\
\hline Total: & 100.00 & 100.00 \\
\hline
\end{tabular}

(a) Before oxidation

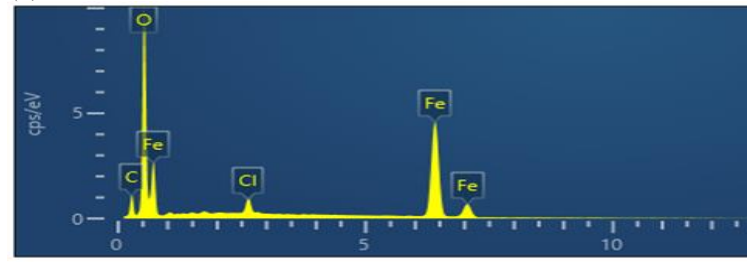

\begin{tabular}{|c|c|c|}
\hline Element & Weight \% & Atomic \% \\
\hline $\mathrm{C}$ & 9.45 & 22.02 \\
\hline $\mathrm{O}$ & 25.71 & 44.97 \\
\hline $\mathrm{Cl}$ & 1.82 & 1.44 \\
\hline $\mathrm{Fe}$ & 63.02 & 31.57 \\
\hline Total: & 100.00 & 100.00 \\
\hline
\end{tabular}

(b) after oxidation

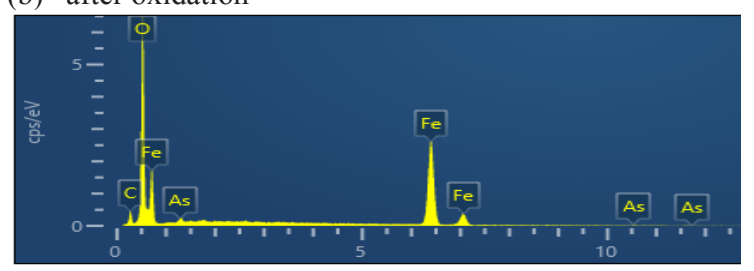

\begin{tabular}{|c|c|c|}
\hline Element & Weight \% & Atomic \% \\
\hline $\mathrm{C}$ & 6.40 & 15.45 \\
\hline $\mathrm{O}$ & 27.88 & 50.56 \\
\hline $\mathrm{Fe}$ & 64.54 & 33.53 \\
\hline $\mathrm{As}$ & 1.19 & 0.46 \\
\hline Total: & 100.00 & 100.00 \\
\hline
\end{tabular}

(c) after arsenic removal

Fig. 3. EDS analysis of iron oxide on nail surface

To study the distribution of Fe, $\mathrm{O}$ and as on nails, EDS mapping was conducted on oxidized nails after arsenic removal experiments (Fig. 4) $\mathrm{Fe}$ and $\mathrm{O}$ atoms are distributed over the entire surface. Notably, $\mathrm{O}$ atom were the most prevalent, and adsorbed as was observed over the entire surface. Together, these suggest that iron oxide was uniformly formed on iron nails and that arsenic is removed evenly on iron nails without preference for specific sites.

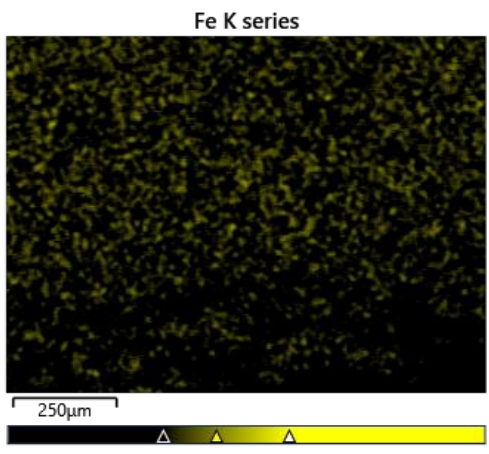

Fe mapping

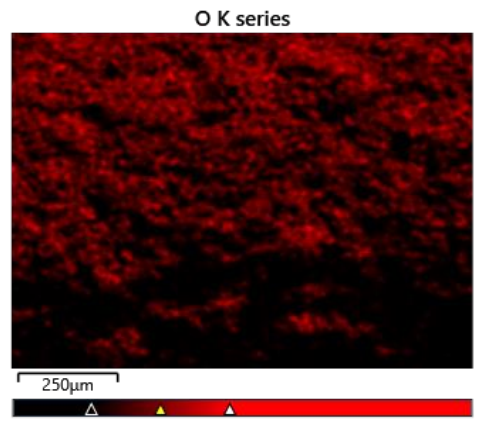

O mapping

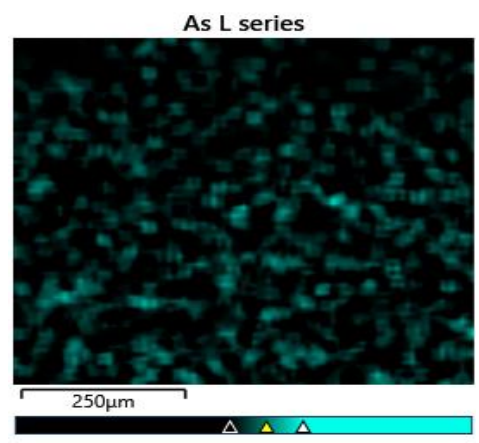

As mapping

Fig. 4. EDS mapping image of oxidized iron after arsenic removal 


\subsection{XRD analysis}

Fig. 5 (a) shows the XRD analysis of iron oxide formed using peracetic acid. Iron oxide is mostly amorphous, which is to be expected since most compounds formed in aqueous solution are amorphous. However, weak crystal peaks are observed near $2 \theta=24^{\circ}$ and $33^{\circ}$, which are indicated as $\boldsymbol{\Delta}$, which corresponds to the $\mathrm{Fe}_{2} \mathrm{O}_{3}$ crystal peak (see small figure).

The results of the study on the removal of heavy metals of amorphous $\mathrm{Fe}_{2} \mathrm{O}_{3}$ have not been reported yet, but Pierce reported that the removal efficiency of heavy metals using amorphous $\mathrm{Fe}(\mathrm{OH})^{3}$ was higher than that of crystalline $\mathrm{Fe}(\mathrm{OH})^{3}$ [3]. One of the reasons for the high removal efficiency is that amorphous iron oxide has a larger specific surface area than crystalline iron oxide. made of acetic peroxide has a wide specific surface area.

Fig. 5 (b) shows the XRD pattern of iron oxide made with nitric acid for comparison. The iron oxide made with nitric acid is $\mathrm{FeO}(\mathrm{OH})$ and has a low crystallinity. Saha reported that the heavy metal removal rate of amorphous $\mathrm{FeO}(\mathrm{OH})$ was higher than that of other iron oxides [4].

\subsection{Surface area and Pore size distribution analysis}

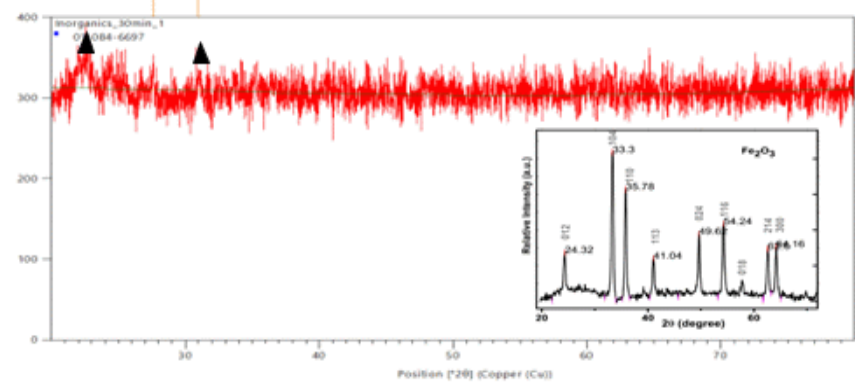

(a) iron oxide made by peracatic acid

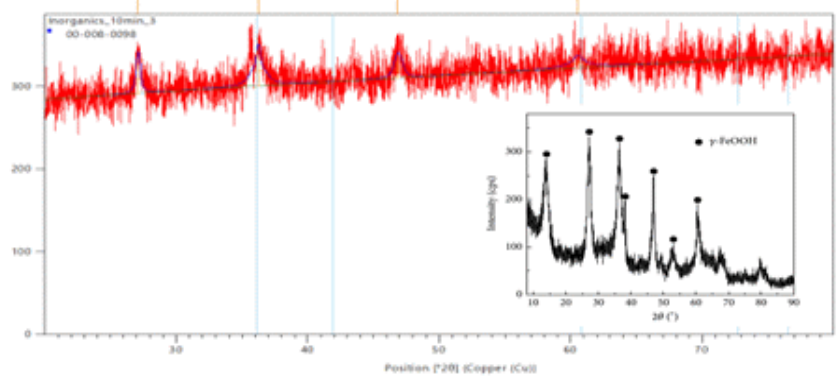

(b) iron oxide made by nitric acid

Fig. 5. X-ray diffraction (XRD) of iron oxide on nails.

The isotherm graph was shown at Fig. 6. The specific surface area of rust calculated from the BET equation was $71 \mathrm{~m}^{2} / \mathrm{g}$. Compared to the commercially sold $\mathrm{Fe}^{2} \mathrm{O}^{3}$ powders with a specific surface area of about $10 \mathrm{~m}^{2} / \mathrm{g}$, $\mathrm{Fe}^{2} \mathrm{O}^{3}$ made of acetic peroxide has a relatively large specific surface area. The pore types from the shape of the desorption curve and hysteresis are plate or rod, and the pores of micro-size and meso-size are present together [5].

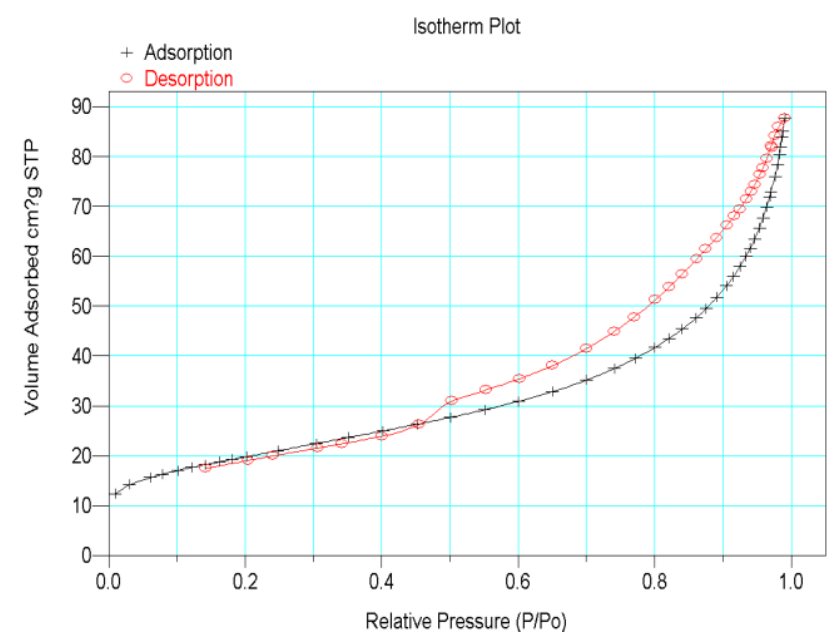

Fig. 6. Isotherm plot of $\mathrm{Fe} 2 \mathrm{O} 3$ on nails.

Pore size distribution graph was shown at Fig. 7. The average pore size calculated from the $\mathrm{BJH}$ equation is $71 \sim 75 \AA$, and from the $\mathrm{dA} / \mathrm{dD}$ graph, there are few pores with a diameter of $100 \AA$ or more and relatively many pores with a diameter of $40 \AA$.

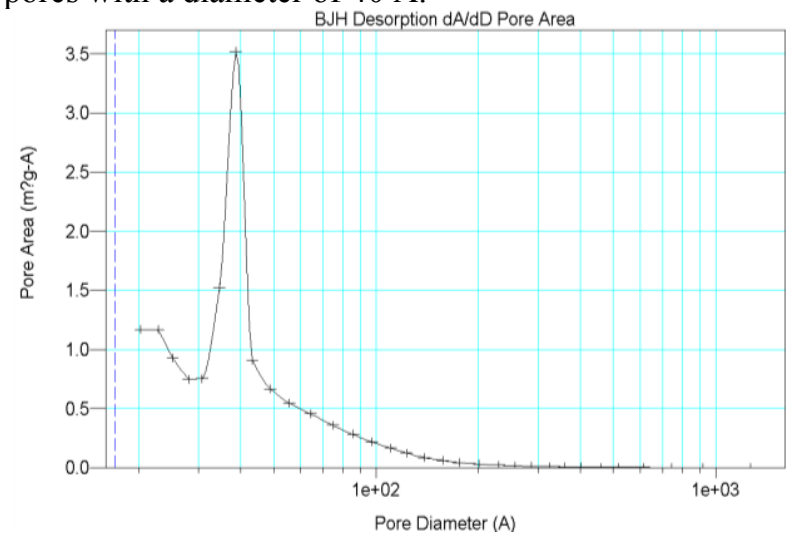

Fig. 7. Isotherm adsorption/desorption plot and $\mathrm{BJH} \mathrm{dA} / \mathrm{dD}$ plot of iron oxide rust

\subsection{Arsenic removal in water using rust of oxidized nails}

\subsubsection{Removal of arsenic with residence time}

The results of the experiment for removing arsenic with a concentration of $1 \mathrm{ppm}$ using rust made of acetic peroxide and nitric acid were shown in Fig. 8.

At $5 \mathrm{~min}$, the arsenic removal rate of rust made from acetic peroxide was $83 \%$ and the arsenic removal rate of rust made from nitric acid was $45 \%$. At $10 \mathrm{~min}$, the arsenic removal rate of rust made from nitric acid was $84 \%$ and $65 \%$, at $20 \mathrm{~min}, 87.4 \%$ and $89.4 \%$, at $30 \mathrm{~min}$, $90.4 \%$ and $92.5 \%$, at $40 \mathrm{~min}, 91.7 \%$ and $94.3 \%$. 


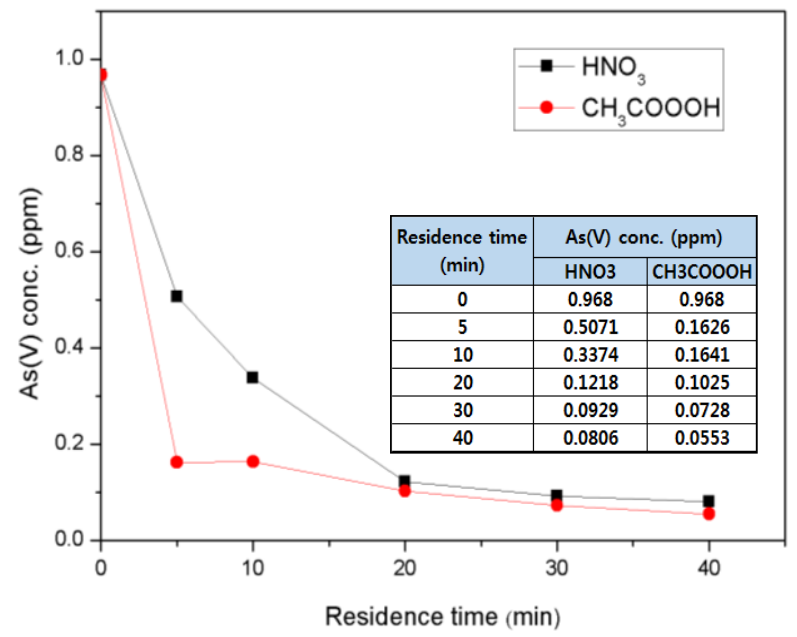

Fig. 8. Arsenic removal as a function of residence time

The arsenic removal rate of amorphous $\mathrm{Fe}^{2} \mathrm{O}^{3}$ rust made with acetic peroxide was higher than that made with nitric acid. As the residence time increase, the removal rate of arsenic also increases, but the increasing rate is low at 20 minutes or more. It is a very meaningful results that $83 \%$ of arsenic removal rate was obtained by treating $1 \mathrm{ppm}$ arsenic solution for 5 minutes with rusted nails.

\subsubsection{Change of arsenic removal rate with repeated experiment}

The results of the experiment were shown at Fig. 9 after 10 times of arsenic removal experiment with the initial arsenic concentration at $1.014 \mathrm{ppm}$ for 20 minutes. The removal rate of arsenic was between $87.9 \%$ and $93.3 \%$. This shows that the efficiency of arsenic removal has not been reduced even in 10 repeated experiments considering the experimental error, and the nail can still adsorb arsenic.

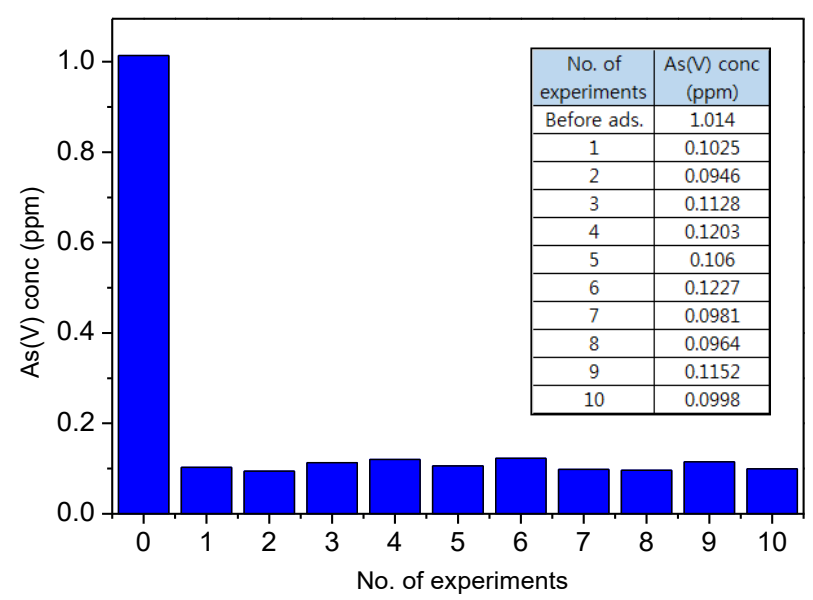

Fig. 9. Ten repeated experiments for Arsenic removal

\subsubsection{Maximum arsenic adsorption measurement}

To design arsenic removal device, it is necessary to know the maximum amount of arsenic adsorption per unit area of the rusted nail. To achieve this, arsenic concentration was measured after 12 hours with two oxidized nails with peracetic acid in a $50 \mathrm{ml}$ aqueous solution of $8.91 \mathrm{ppm}$ arsenic concentration. The arsenic concentration was decreased from 8.91ppm to $1.17 \mathrm{ppm}$ (Fig. 10). From this result, the maximum amount of arsenic that can be removed per rusted nail is $0.194 \mathrm{mg}$, and the amount of arsenic that can be removed per unit area is $0.114 \mathrm{mg}$.

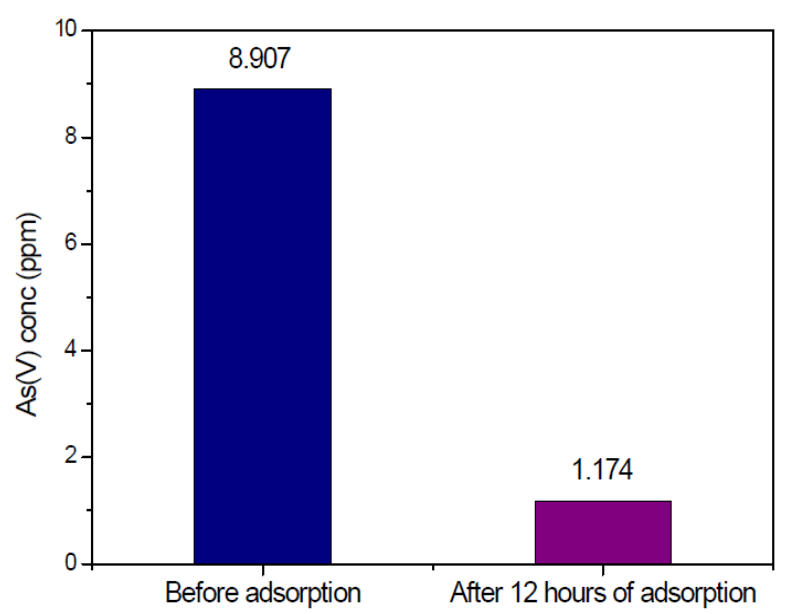

Fig. 10. Maximum amount of arsenic adsorption.

\section{Conclusions}

(1) $\mathrm{Fe}_{2} \mathrm{O}_{3}$ was easily synthesized on iron nails using peracetic acid. As prepared $\mathrm{Fe}_{2} \mathrm{O}_{3}$ was amorphous and had a large specific surface area of $71 \mathrm{~m}^{2} \mathrm{~g}^{-1}$ and a average pore diameter of $73 \AA$.

(2) Rust of oxidized nails are highly effective for removing heavy metals: $90 \%$ of arsenic in water was removed at the residence time of 20 minutes.

(3) Oxidized iron nails are robust and maintain their removal rate of $90 \%$ after 10 back-to-back arsenic removal experiments at the residence time of 20 minutes.

(4) Each oxidized nail removed up to $0.194 \mathrm{mg}$ of arsenic, sand iron oxide prepared in this study can remove, per 1 $\mathrm{cm}^{2}$, up to $0.114 \mathrm{mg}$ of arsenic.

\section{References}

1. K. A. Al-Saad, Arab Journal of Nuclear Sciences and Applications, 45(2) (2012)

2. P. Toniolo, Dr. Domenico Santoro, ECI Symposium Series, (2014)

3. M. L. Pierce, Water Research, 16 (7), (1982)

4. B. Saha, Sep. Sci. Technol., 40(14) (2005)

5. M. Thomas, Physisorption of gases, Pure Appl. Chem. (2015) 